\title{
Alkali environments in tellurite glasses
}

\author{
Emma R. Barney ${ }^{l^{*}}$, Alex C. Hannon ${ }^{2}$, Diane Holland ${ }^{3}$, Norimasa Umesaki ${ }^{4}$ and \\ Masahiro Tatsumisago 5
}

\begin{abstract}
${ }^{1}$ Faculty of Engineering, University of Nottingham, Nottingham, NG7 2RD, UK
${ }^{2}$ ISIS Facility, Rutherford Appleton Laboratory, Chilton, Didcot, OX11 OQX, UK

${ }^{3}$ Physics Department, University of Warwick, Coventry, CV4 7AL, UK

${ }^{4}$ Division of Materials and Manufacturing Science, Osaka University, Suita, Osaka 565-0871, Japan

${ }^{5}$ Department of Applied Materials Science, Osaka Prefecture University, Sakai, Osaka 599-8531, Japan
\end{abstract}

*Corresponding author emma.barney@nottingham.ac.uk

\section{Abstract}

Neutron diffraction measurements are reported for five binary alkali tellurite glasses, $x \mathrm{M}_{2} \mathrm{O} \cdot(100-x) \mathrm{TeO}_{2}$ (containing 10 and $20 \mathrm{~mol} \% \mathrm{~K}_{2} \mathrm{O}, 10$ and $19 \mathrm{~mol} \% \mathrm{Na}_{2} \mathrm{O}$, and $20 \mathrm{~mol} \%$ ${ }^{7} \mathrm{Li}_{2} \mathrm{O}$ ), together with ${ }^{23} \mathrm{Na}$ MAS NMR measurements for the sodium containing glasses. Differences between neutron correlation functions are used to extract information about the local environments of lithium and sodium. The $\mathrm{Na}-\mathrm{O}$ bond length is $2.37(1) \AA$ and the average $\mathrm{Na}-\mathrm{O}$ coordination number, $n_{\mathrm{NaO}}$, decreases from $5.2(2)$ for $x=10$ mol\% $\mathrm{Na}_{2} \mathrm{O}$ to 4.6(1) for $x=19$ mol\% $\mathrm{Na}_{2} \mathrm{O}$. The average $\mathrm{Li}-\mathrm{O}$ coordination number, $n_{\mathrm{LiO}}$, is $3.9(1)$ for the glass with $x=20$ mol\% $\mathrm{Li}_{2} \mathrm{O}$ and the $\mathrm{Li}-\mathrm{O}$ bond length is $2.078(2) \AA$. . As $x$ increases from 10 to 19 mol\% $\mathrm{Na}_{2} \mathrm{O}$, the ${ }^{23} \mathrm{Na}$ MAS NMR peak moves downfield, confirming an earlier report of a correlation of peak position with sodium coordination number. The close agreement of the maximum in the Te-O bond distribution for sodium and potassium tellurite glasses of the same composition, coupled with the extraction of reasonable alkali coordination numbers using isostoichiometric differences, gives strong evidence that the tellurium environment in alkali tellurites is independent of the size of the modifier cation used.

\section{Introduction}

The local structure of alkali $\mathrm{M}_{2} \mathrm{O}-\mathrm{TeO}_{2}$ glasses ( $\mathrm{M}=\mathrm{Li}, \mathrm{Na}$, and $\mathrm{K}$ ) has been studied extensively using neutron diffraction [1-5], X-ray diffraction [6,7], EXAFS [7,8], Raman scattering $[7,9,10]$, NMR $[2,11-13]$ and RMC modelling $[2,14]$. In these studies, particular Page 1 
emphasis was placed on determining the local environment of tellurium and there is a general consensus that the average tellurium coordination number, $n_{\mathrm{TeO}}$, decreases as an oxide modifier is added to the glass network, the change being driven by the bonding requirements of the modifier. In a silicate glass, the number of non-bridging oxygens (NBOs) provided by one unit of $\mathrm{M}_{2} \mathrm{O}$ cannot support the number of $\mathrm{M}-\mathrm{O}$ bonds needed to satisfy the bonding requirements of the $\mathrm{M}^{+}$ions, necessitating the formation of less favourable bonds to bridging oxygens (BOs), as well as M-NBO bonds. However, in the tellurite glass system the local tellurium environment may be either pseudo-bipyramidal, $\left[\mathrm{TeO}_{4} \mathrm{E}\right]$, or pseudo-tetrahedral, $\left[\mathrm{TeO}_{3} \mathrm{E}\right]$ (where $\mathrm{E}$ denotes a lone-pair of electrons). The former are found in pure crystalline $\alpha-\mathrm{TeO}_{2}$ [15], while the latter have an arrangement of atoms similar to that present in $\mathrm{M}_{2} \mathrm{TeO}_{3}$ crystals [16-18]. The change in the local environment of a $\mathrm{Te}$ atom from $\left[\mathrm{TeO}_{4} \mathrm{E}\right]$ to $\left[\mathrm{TeO}_{3} \mathrm{E}\right]$ provides an additional $\mathrm{NBO}$ in the network, and hence reduces the total number of unfavourable M-BO bonds needed to fulfil the bond requirements of the $\mathrm{M}^{+}$ions [19].

A detailed knowledge of the behaviour of the $\mathrm{M}-\mathrm{O}$ coordination is important for the development of a reliable model for the composition-dependence of the Te-O network in $\mathrm{M}_{2} \mathrm{O}-\mathrm{TeO}_{2}$ glasses [19]. However, there are few direct observations of the local environment of an alkali ion in alkali tellurite glasses and the results of these studies are now summarised. A neutron diffraction study of lithium tellurite glasses [1] was interpreted as showing that lithium is coordinated by 4 oxygen atoms with a Li-O bond length of $\sim 2 \AA$. For sodium tellurite glasses, a ${ }^{23} \mathrm{Na}$ dynamic angle spinning (DAS) NMR study showed that the coordination number of sodium drops from $\sim 5.8$ to 5.2 with increasing $\mathrm{Na}_{2} \mathrm{O}$ content [11]. Molecular orbital calculations have also been performed for cluster models of sodium tellurite glasses [4] and $\mathrm{Na}-\mathrm{O}$ coordinations of 3, 4 and 5 were found. It was concluded that the 5-coordinated environment is more representative of the glass, based on the results of the previous ${ }^{23} \mathrm{Na}$ NMR study [11]. An Extended X-ray Absorption Fine Structure (EXAFS) and X-ray diffraction (XRD) study of two potassium tellurite glasses [7] indicated that the K-O coordination number, $n_{\mathrm{KO}}$, is 6 , with $\mathrm{K}-\mathrm{O}$ bond lengths of $2.71 \AA$. However, a second study, using neutron and X-ray diffraction to investigate three potassium tellurite glasses, determined that the $\mathrm{K}-\mathrm{O}$ contribution to the results was too small to allow the coordination Page 2 
to be determined. To interpret the results, an assumed $K$ environment of 3 oxygen atoms at $2.67 \AA$ and 4 oxygen atoms at $2.88 \AA$ was used [5]. Finally, a series of Reverse Monte Carlo (RMC) simulations of neutron and X-ray diffraction data for lithium, sodium and potassium tellurites has been performed [3], but the local environment of the alkali atoms was not determined; instead information from related crystal structures $\left(\mathrm{Na}_{2} \mathrm{Te}_{4} \mathrm{O}_{9}[20], \mathrm{K}_{2} \mathrm{Te}_{4} \mathrm{O}_{9}\right.$ [21], $\mathrm{Li}_{2} \mathrm{Te}_{2} \mathrm{O}_{5}$ [22]) was used to constrain the coordination numbers and bond lengths of the alkali ions, in order to calculate the Te-O bond distribution for $\mathrm{Li}, \mathrm{Na}$ and $\mathrm{K}$ modified glasses. The results obtained were difficult to interpret, showing no trends with modifier type, or concentration. This is likely to be due to the difficulties in deconvoluting the overlapping M$\mathrm{O}$ and Te-O components in the correlation function, $T(r)$.

Neutron diffraction data are presented here for a series of alkali tellurite glasses, $x \mathrm{M}_{2} \mathrm{O}$.(1x) $\mathrm{TeO}_{2}$, modified by 10 and $20 \mathrm{~mol} \% \mathrm{~K}_{2} \mathrm{O}, 10$ and $19 \mathrm{~mol} \% \mathrm{Na}_{2} \mathrm{O}$, and $20 \mathrm{~mol} \%{ }^{7} \mathrm{Li}_{2} \mathrm{O}$. Isostoichiometric difference functions, $\Delta T(r)$, for glasses of equivalent $x$ but different $\mathrm{M}$, may remove the Te-O and Te-Te contributions to $T(r)$, to leave only correlations arising from the modifier. However, this will only be the case if the Te-O bond distribution is independent of M. Several Raman studies of alkali tellurite glasses have shown that $n_{\mathrm{TeO}}$ is relatively unaffected by the size of modifying cation $[10,23]$ and a quantitative model [19], proposed by the Authors to predict the observed change in Te-O coordination number (measured by neutron diffraction) with potassium oxide content, is independent of the alkali coordination number, and hence alkali type. Therefore, the objectives of this study are two-fold; to extract information about the local environment of alkali ions in tellurite glasses and to investigate whether the Te-O environment in alkali tellurites is indeed independent of the modifier used.

\section{Experimental detail}

\subsection{Sample preparation}

Sodium tellurite glasses with nominal compositions of 10 and 20 mol\% $\mathrm{Na}_{2} \mathrm{O}$ were prepared at Warwick University by placing a suitable mixture of $\mathrm{Na}_{2} \mathrm{CO}_{3}$ (Alfa Aesar, 99.95 mol\%) and $\mathrm{TeO}_{2}$ (Alfa Aesar, $99.99 \mathrm{~mol} \%$ ) in $\mathrm{Pt} / \mathrm{Rh}$ crucibles and heating to $800^{\circ} \mathrm{C}$, at a ramp rate of $5^{\circ} \mathrm{C} /$ minute. The glass melt was held at temperature for 15 minutes before being splat- 
quenched using steel plates. Density measurements were carried out using a Quantachrome Micropycnometer with helium as the displacement fluid.

The lithium (Li20) and potassium (K10 and K20) tellurite glasses were made at Osaka Prefecture University, as described previously [7]. The potassium tellurites were made using $\mathrm{K}_{2} \mathrm{CO}_{3}$ and $\mathrm{TeO}_{2}$ as precursors and the lithium tellurite glass was made using enriched ${ }^{7} \mathrm{Li}_{2} \mathrm{CO}_{3}$. The reported lower limit of glass formation for lithium tellurites in older literature is about 13 mol\% $\mathrm{Li}_{2} \mathrm{O}$ [24]. Therefore, whilst it must be acknowledged that lower $\mathrm{Li}_{2} \mathrm{O}$ containing glasses have subsequently been reported in the literature (see $[10,23]$ ) no attempt was made to produce a sample containing $10 \mathrm{~mol} \%{ }^{7} \mathrm{Li}_{2} \mathrm{O}$ for this study.

\subsection{Nuclear magnetic resonance}

Quantitative ${ }^{23} \mathrm{Na}$ magic angle spinning (MAS) NMR spectra were recorded at Warwick University at an applied field of $14.1 \mathrm{~T}$ using a Varian 600 spectrometer operating at a Larmor frequency of $158.747 \mathrm{MHz}$. A known mass of sample was loaded into a $3.2 \mathrm{~mm}$ rotor which was subject to a spinning speed of $15 \mathrm{kHz}$ in a Varian Chemagnetic probe. A single pulse program was used with a $0.7 \mu$ s pulse width and $1 \mathrm{~s}$ pulse delay (sufficiently long to give quantitative spectra). All the chemical shifts were referenced to the secondary reference, solid $\mathrm{NaCl}$, at $7.2 \mathrm{ppm}$ with respect to the primary reference, aqueous $0.1 \mathrm{M} \mathrm{NaCl}$ [25]. The Na content of each sample was determined by comparison of its ${ }^{23} \mathrm{Na}$ signal with that from a known mass of sodium carbonate.

\subsection{Neutron diffraction}

Neutron diffraction measurements on the sodium tellurite glasses were made using the GEM diffractometer [26] at the ISIS Facility. Cylindrical $8.3 \mathrm{~mm}$ diameter vanadium containers with wall thickness $25 \mu \mathrm{m}$ were used to contain the samples. The data were corrected using the Gudrun programme [27] and the Atlas suite of software [28], leading to the distinct scattering, $i(Q)$, shown in (Figure 1). The former LAD diffractometer [29] at the ISIS Facility was used to measure $i(Q)$ for each of the potassium and lithium tellurite glasses (Figure 1), in a $8.0 \mathrm{~mm}$ diameter container with wall thickness $25 \mu \mathrm{m}$. The experimental corrections were performed in the same way as for the sodium tellurite glasses, allowing the Page 4 
results to be directly compared. The neutron diffraction data, in both reciprocal- and realspace, are available from the ISIS Disordered Materials Database [30].

For each sample, the corrected $i(Q)$ was Fourier transformed (using the Lorch modification function [31] with a maximum momentum transfer, $Q_{\max }$, of $35 \AA^{-1}$ ) to yield the correlation function, $T(r)$ (see Hannon [32] for further theoretical details). A diffraction experiment is not element specific, and $T(r)$ is a weighted sum of all possible partial correlation functions, $t_{u u^{r}}(r)$

$$
T(r)=\sum_{u^{\prime}} c_{l} \bar{b}_{l} \bar{b}_{l^{\prime}} t_{u^{\prime}}(r)
$$

where $c_{l}$ is the atomic fraction of element $l$ and $\bar{b}_{l}$ and $\bar{b}_{l^{r}}$ are the coherent neutron scattering lengths for elements $l$ and $l^{\prime}$ respectively. All the pairwise combinations of elements in the sample are included in the summation. A peak in $T(r)$ that arises solely from interatomic distances between atoms of element $l$ and $l^{\prime}$ can be fitted to determine the area, $A_{u^{r}}$, and position, $r_{u^{r}}$, for the peak. Using these parameters, along with the weighting coefficient for $t_{u}(r)$ in Equation (1), the coordination number, $n_{u u^{r}}$, can be calculated according to

$$
n_{u u^{r}}=\frac{r_{u u^{r}} A_{u^{r}}}{\left(2-\delta_{u u^{r}}\right) c_{l} \bar{b}_{l} \bar{b}_{l^{r}}}
$$

where $\delta_{u u^{r}}$ is the Kronecker delta.

\section{Results}

The densities measured for the sodium tellurite glasses (Table 1) are shown with literature values [33-35] in Figure 2. The glass compositions were redetermined as 9.5 and 18.8 mol\% $\mathrm{Na}_{2} \mathrm{O}$ by comparing the measured densities with a line of best fit through the literature data 
(Table 1). A second measure of sodium content was obtained from the quantitative ${ }^{23} \mathrm{Na}$ NMR. The NMR-derived compositions (Table 1) agree, within error, with those obtained from density measurements, and hence the neutron diffraction data for these two samples were corrected and analysed using the average redetermined compositions, 10 and 19 mol\% $\mathrm{Na}_{2} \mathrm{O}$. Note that in a previous study of boron tellurite glasses [36] we have successfully used the same approach to redetermine the composition of glass samples. Although the precursor chemicals were carefully weighed, $\mathrm{Na}_{2} \mathrm{CO}_{3}$ is hygroscopic and the powders were not dried prior to weighing. Any water content in $\mathrm{Na}_{2} \mathrm{CO}_{3}$ would reduce the amount of $\mathrm{Na}_{2} \mathrm{O}$ in the final melt, and this may be the reason for the slight reduction of $\mathrm{Na}_{2} \mathrm{O}$ in the $\mathrm{Na} 19$ sample. The loss in $\mathrm{Na}_{2} \mathrm{O}$ from the $\mathrm{Na} 19$ sample is not large enough to have a significant effect on the differences discussed below, but for future studies, where accurate differences between different glasses of the same composition are required, it would be advantageous to use dried $\mathrm{Na}_{2} \mathrm{CO}_{3}$. Neutron diffraction is very sensitive to the presence of hydrogen in a sample (due to the large incoherent cross section of hydrogen, and the severe effects of inelasticity for this nucleus); however, the neutron diffraction data showed no evidence of hydrogen in the samples, indicating that the glass samples were essentially dry.

The ${ }^{23} \mathrm{Na}$ MAS NMR spectra for the $\mathrm{Na} 10$ and Na19 glasses exhibit a single broad peak (Figure 3) and the position of the peak for the Na19 glass ( 1 ppm) is shifted downfield by $+3 \mathrm{ppm}$ with respect to that for Na10 (Table 1). This can be characteristic of a decrease in shielding of the nucleus - i.e. a more ionic environment [13].

The neutron diffraction patterns of the samples (see Figure 1) do not exhibit any Bragg peaks. Pulsed neutron diffraction is very sensitive to the presence of crystallinity in a sample, due to its high resolution in reciprocal-space, and its highly penetrating nature, and hence this is strong evidence of the lack of crystallinity of the samples. The total correlation functions, $T(r)$ (Figure 4), exhibit two peak maxima at $\sim 1.9$ and $2.8 \AA$, which may be assigned to Te-O bonds and $\mathrm{O} \ldots \mathrm{O}$ distances respectively and thus arise from the Te-O network. It is important to note that the distribution of Te-O bond lengths in tellurite glasses [19] extends over a wide range of interatomic distances (say $\sim 1.8-2.4 \AA$ ). The Page 6 
expected positions for the M-O contributions to $T(r)$ are indicated by arrows in Figure 4; although there is a change in intensity at the expected positions, clear, resolved $\mathrm{M}-\mathrm{O}$ peaks are not observed. For the potassium tellurite glasses (K10 and K20), $T(r)$ has a more intense peak at $\sim 2.8 \AA$ than for the corresponding Li and Na glasses, and this can be attributed to KO bonds. Conversely, the Li20 glass has a less intense peak at $1.9 \AA$ than the K20 and Na19 glasses (Figure $4 \mathrm{~b}$ ), due to the presence of $\mathrm{Li}-\mathrm{O}$ bonds (the coherent neutron scattering length of ${ }^{7} \mathrm{Li}$ is negative, $-2.22 \mathrm{fm}$ [37], and hence the Li-O contribution to $T(r)$ is negative).

Finally, there is an increased intensity in the $\mathrm{Na}_{2} \mathrm{O}$ modified glasses at $\sim 2-2.5 \AA$; this distance range is consistent with $\mathrm{Na}-\mathrm{O}$ bond lengths in crystalline $\mathrm{Na}_{2} \mathrm{Te}_{4} \mathrm{O}_{9}[20]$.

\section{Discussion}

\section{1. ${ }^{23} \mathrm{Na}$ magic angle spinning NMR}

Using DAS NMR, at two fields, Tagg et al. [11] were able to extract isotropic chemical shift, $\delta_{\text {iso }}^{\mathrm{CS}}$, and quadrupole parameter, $P_{\mathrm{Q}}$, values, for glasses similar to those studied here. In contrast, our MAS NMR spectra are broadened by the second-order quadrupole interaction. The peaks shown in Figure 3 are near-symmetric and featureless and, since they were measured at a single field only, it is not possible to obtain an unambiguous fit to give values of $\delta_{\mathrm{iso}}^{\mathrm{CS}}$, and $\mathrm{P}_{\mathrm{Q}}$. Indeed, a major contribution to the peak width is the distribution of sodium environments which results in corresponding distributions of both $\delta_{\mathrm{iso}}^{\mathrm{CS}}$, and $P_{\mathrm{Q}}$, and Tagg et al. used simulation of their DAS spectra to show that the distribution widths are approximately $5 \mathrm{ppm}$ for $\delta_{\text {iso }}^{\mathrm{CS}}$ and $0.75 \mathrm{MHz}$ for the quadrupolar coupling constant, $C_{\mathrm{Q}}$ (assuming that $P_{Q}=C_{Q}\left(1+\eta^{2} / 3\right)^{0.5} \approx C_{Q}$ for small asymmetry parameter, $\left.\eta\right)$. The peak positions of the ${ }^{23} \mathrm{Na}$ spectra from the 10 and $19 \mathrm{~mol} \% \mathrm{Na}_{2} \mathrm{O}$ samples reported in Table 1 are also affected by the second-order quadrupole effect, though the higher field used in the current study $(14.1 \mathrm{~T})$ means that the position of the peak maximum is closer to the isotropic shift as a consequence of the smaller quadrupole induced shift $\left(1 / v_{0}^{2}\right.$ dependence where $v_{0}$ is the Larmor frequency). Data from Tagg (after adjustment of the shift values to the primary reference by adding $7.2 \mathrm{ppm}$ ) can be used to predict where the most probable 
isotropic shift should be at 14.1 T (see Appendix 1). The values of -5.7(3.0) and -1.4(3.0) ppm obtained are close to the $-2.0(5)$ and $+0.8(5)$ ppm of the peak maxima $(-2.1(5)$ and $0.2(5)$ ppm c.o.g) for the 10 and 19 mol\% $\mathrm{Na}_{2} \mathrm{O}$ glasses. The change in the peak positions with composition observed in the current study is consistent with the changes in isotropic shift derived by Tagg et al. [11]. Their more detailed study (8 samples from 10 to 33 mol\% $\mathrm{Na}_{2} \mathrm{O}$ ) showed that there is a step-change in $\delta_{\text {iso }}^{\mathrm{CS}}$ and $\mathrm{PQ}_{\mathrm{Q}}$ at about $15 \mathrm{~mol} \% \mathrm{Na}_{2} \mathrm{O}$, close to the composition where a change in Te environment is proposed by our structural model for tellurites [19]. By means of an empirical relation derived by Koller et al., [38] they used their values of $\delta_{\text {iso }}^{\mathrm{CS}}$ to estimate the average coordination number of sodium in their sodium tellurite glasses, giving $n_{\mathrm{NaO}}=5.8$ and 5.5 for the glasses containing 10 and 20 mol\% $\mathrm{Na}_{2} \mathrm{O}$ respectively.

\subsection{The isostoichiometric difference method.}

For conventional glasses, such as silicates, information on the modifier environment, including coordination number and distribution of bond lengths, may be determined from neutron correlation functions by means of the traditional difference technique [39]. This technique involves making a suitable subtraction of two correlation functions for glasses from the same system with different compositions. For example, for sodium silicate glasses the difference may be taken between measurements of $T(r)$ for two $\mathrm{Na}_{2} \mathrm{O}-\mathrm{SiO}_{2}$ samples with different $\mathrm{Na}_{2} \mathrm{O}$ content. Although there is some overlap of the first $\mathrm{Na}-\mathrm{O}$ peak with the first $\mathrm{O}-\mathrm{O}$ peak (which arises from distances in $\mathrm{SiO}_{4}$ tetrahedra), the $\mathrm{O}-\mathrm{O}$ coordination number can be predicted reliably and the changes in the width of the O-O peak are sufficiently small that the difference yields tractable results on the $\mathrm{Na}-\mathrm{O}$ distribution [39].

The situation for tellurite glasses is rather different, because the $\mathrm{Te}-\mathrm{O}$ coordination number depends on the modifier content, and the Te-O bond lengths are widely distributed. For example, for potassium tellurite glasses, neutron diffraction results [19] have shown that the Te-O bond length distribution changes significantly with increasing modifier concentration; as $\mathrm{K}_{2} \mathrm{O}$ is added, the average Te-O bond length shortens and, for more than 15 mol\% $\mathrm{K}_{2} \mathrm{O}, n_{\text {TeO }}$ reduces steadily with composition. For sodium tellurite glasses, the $\mathrm{Na}-\mathrm{O}$ 
distribution has a large overlap with the Te-O distribution, as well as some overlap with the $\mathrm{O}-\mathrm{O}$ peak. As a consequence of this large overlap, together with the variation in the $\mathrm{Te}-\mathrm{O}$ coordination and distribution of bond lengths, the traditional difference technique is not useful for tellurite glasses. However, as we show in this paper, significant progress can be made by instead taking the difference between two measurements of $T(r)$ that are isostoichiometric. i.e. for two alkali glasses with the same alkali content, but different alkali metal cations. For example, if $T(r)$ is measured for a sodium tellurite glass and a potassium tellurite glass of the same alkali content, then the isostoichiometric difference may be defined as

$$
\Delta T(r)_{\mathrm{Na}-\mathrm{K}}=T(r)_{\mathrm{Na}}-T(r)_{\mathrm{K}}
$$

where $T(r)_{\mathrm{M}}$ is the correlation function measured for a $\mathrm{M}_{2} \mathrm{O}-\mathrm{TeO}_{2}$ glass of the specified composition. Figure 5 shows $\Delta T(r)_{\mathrm{Na10-K} 10}$ and $\Delta T(r)_{\mathrm{Na19}-\mathrm{K} 20 .}$. The positive peak at $\sim 2.35 \AA$ is due to $\mathrm{Na}-\mathrm{O}$ bonds, and the negative peak at $2.82 \AA$ to $\mathrm{K}-\mathrm{O}$ bonds. A single Na-O peak was fitted to each $\Delta T(r)_{\mathrm{Na}-\mathrm{K}}$ in the region 2.05-2.60 $\mathrm{A}$, which encompasses the entire positive peak (Figure 5). The parameters for the fits (Table 2) yield $\mathrm{Na}-\mathrm{O}$ coordination numbers of 4.4(1) and 4.1(1) for Na10 and Na19 respectively.

In principle, the only experimental technique that can yield a wholly satisfactory separation of partial correlation functions is neutron diffraction isotopic substitution [40]; neutron diffraction is measured for samples that have identical structure and chemical composition, but have different isotopic composition for one or more elements, so that the scattering length of a substituted element is altered (see Equation (1)). In practice, neutron diffraction isotopic substitution is of limited application, due to several factors: for some elements, suitable isotopes do not exist; for some elements, the difference in scattering lengths is small; most isotopes are very expensive; it can be challenging to make samples that are identical. Thus there has been extensive use of the method of isomorphic substitution [4145]; neutron or X-ray diffraction is measured for samples that have identical structure and chemical composition, except that one element is substituted for another, and it is assumed that the structural role of the two elements concerned is the same. For isomorphic Page 9 
substitution to be applicable, the two elements concerned must have very similar chemistry and bond lengths. We propose that a useful criterion for whether two elements of the same valence are amenable to isomorphic substitution is that the difference in their oxygen bondvalence parameters [46] should not be larger than $\sim 0.01 \AA$. Clearly the alkali elements are not suitable for isomorphic substitution, because their oxygen bond-valence parameters differ by $\sim 0.3 \AA$. Or, to put it another way, the alkali elements are not suitable for isomorphous substitution because their ionic radii are markedly different [47]. However, as we show by the consideration given in this paper, it may be possible to measure useful information on the alkali coordination by means of isostoichiometric differences. The successful use of the isostoichiometric difference method has recently been reported for LiNa substitution [48] and for Ca-Sr substitution [49], both in bioactive glasses. In these two reports the technique was described as isomorphic, but this is an incorrect use of the term, because Li and $\mathrm{Na}$ (and similarly $\mathrm{Ca}$ and $\mathrm{Sr}$ ) are not even approximately isomorphous.

For a binary glass, such as an alkali tellurite, $\mathrm{M}_{2} \mathrm{O}-\mathrm{TeO}_{2}, T(r)$ is a weighted sum of six independent pairwise partial correlation functions, $t_{u u^{r}}(r)$, as given by equation (1). However, in the region of interest for $\mathrm{Na}-\mathrm{O}$ bonds (i.e. for $r^{\sim 2} 2.35 \AA$, the sum of the ionic radii [47]) there is no contribution to $T(r)$ from cation-cation distances (i.e. Te-Te, Te-M and MM). For example, in crystalline $\mathrm{Na}_{2} \mathrm{Te}_{4} \mathrm{O}_{9}$ [20], the shortest cation-cation distance is $3.166 \AA$, between two Te atoms. If cation-cation terms are excluded, then in the region of interest equation (1) reduces to

$$
T(r)=2 c_{\mathrm{M}} \bar{b}_{\mathrm{M}} \bar{b}_{\mathrm{O}} t_{\mathrm{Mo}}(r)+2 c_{\mathrm{Te}} \bar{b}_{\mathrm{Te}} \bar{b}_{\mathrm{O}} t_{\mathrm{TeO}}(r)+c_{\mathrm{O}} \bar{b}_{\mathrm{O}}^{2} t_{\mathrm{OO}}(r)
$$

The reliability of the difference defined by equation (3) as a means of measuring the M-O partial correlation function then depends on the following two factors: F1) The Te-O and O$\mathrm{O}$ terms in equation (4) must be similar in the region of interest, and then the subtraction given in equation (3) will remove them from $\Delta T(r)$. F2) There must be little overlap between the $\mathrm{M}-\mathrm{O}$ and $\mathrm{M}^{\prime}-\mathrm{O}$ peaks for the two different alkali cations, $\mathrm{M}$ and $\mathrm{M}^{\prime}$. If there is 
overlap then, as is shown below, this leads to a reduction in the apparent coordination number.

To investigate the reliability of the isostoichiometric difference method, $T(r)$ was simulated for crystalline $\mathrm{Na}_{2} \mathrm{Te}_{4} \mathrm{O}_{9}$ [20] and crystalline $\mathrm{K}_{2} \mathrm{Te}_{4} \mathrm{O}_{9}$ [21] using the XTAL program [50], as shown in Figure 6a. The effects of real-space resolution and thermal motion were included in the simulations as described in Appendix 2. Figure 6a also shows the $\mathrm{Na}-\mathrm{O}$ and $\mathrm{K}-\mathrm{O}$ contributions to the simulated $T(r)$ for these two crystals. The form of these $M-O$ contributions is typical for $\mathrm{Na}$ and $\mathrm{K}$ cations in oxide crystals, with the main coordination in a narrower main peak at shorter distance, followed by a smaller, broader tail at higher $r$, for which the additional $\mathrm{M}-\mathrm{O}$ coordination number is one. For crystalline $\mathrm{Na}_{2} \mathrm{Te}_{4} \mathrm{O}_{9}$, the main $\mathrm{Na}-\mathrm{O}$ peak has coordination number 4.5 , and is centred at $2.354 \AA$ with RMS variation $0.053 \AA$, whilst the high $r$ tail involves interatomic distances of $2.712 \AA$ and $2.926 \AA$. (For crystalline $\mathrm{K}_{2} \mathrm{Te}_{4} \mathrm{O}_{9}$, the main $\mathrm{K}-\mathrm{O}$ peak has coordination number 6.5 , and is centred at $2.785 \AA$ with $\mathrm{RMS}$ variation $0.128 \AA$, whilst the high $r$ tail involves interatomic distances of $3.248 \AA$ and $3.372 \AA$.) This average short $\mathrm{Na}-\mathrm{O}$ bond length of $2.354 \AA$ is very similar to the positions of the $\mathrm{Na}-\mathrm{O}$ peaks fitted to $\Delta T(r)_{\mathrm{Na}-\mathrm{K}}$ (see Table 2), and there is a clear correspondence between the peak fits and the main $\mathrm{Na}-\mathrm{O}$ peak in $\mathrm{Na}_{2} \mathrm{Te}_{4} \mathrm{O}_{9}$.

The difficulty of extracting information on the $M-O$ coordination from a single measurement of $T(r)$ is illustrated by the simulations shown in Figure 6a. It is also apparent from Figure $6 a$ that the short $\mathrm{Te}-\mathrm{O}$ bonds in the reported structure of $\mathrm{Na}_{2} \mathrm{Te}_{4} \mathrm{O}_{9}$ [20] are longer than in the reported structure of $\mathrm{K}_{2} \mathrm{Te}_{4} \mathrm{O}_{9}[21]$, suggesting a difference in the $\mathrm{Te}-\mathrm{O}$ distribution, depending on the alkali cation; the maximum in the simulated $T(r)$ occurs at $1.91 \AA$ for $\mathrm{Na}_{2} \mathrm{Te}_{4} \mathrm{O}_{9}$, and at $1.89 \AA$ for $\mathrm{K}_{2} \mathrm{Te}_{4} \mathrm{O}_{9}$. However, in contrast, fits to the main $\mathrm{Te}-\mathrm{O}$ peak in $T(r)$ (fitted over the range 1.68-1.92 A) for the glasses (Table 2 ) show significantly less dependence of the mean short Te-O bond length on the alkali cation. It should be noted that Holland et al. have reported a metastable crystal phase for $\mathrm{Na}_{2} \mathrm{Te}_{4} \mathrm{O}_{9}$ that forms first on heating the glass [13]. Although the structure for this crystal phase is unknown, a neutron diffraction study shows that the maximum in the Te-O distribution is at $1.88 \AA$ [51]. Page 11 
This is much closer to that observed in $\mathrm{Na} 19$ and $\mathrm{K} 20$, indicating that the reported crystal structure of the stable form of $\mathrm{Na}_{2} \mathrm{Te}_{4} \mathrm{O}_{9}$ [20] may not be the most suitable for comparison with the glass structure.

The good agreement between the short Te-O bond lengths for $\mathrm{Na10}$ and $\mathrm{K} 10$, and for $\mathrm{Na} 19$ and $\mathrm{K} 20$ reported in Table 2, is evidence that the contribution from $t_{\mathrm{TeO}}(r)$ in $\Delta T(r)_{\mathrm{Na}-\mathrm{K}}$ is very small and negligible: In a Te-O-Te bridge, there is a balance between the lengths and valences of the short and long bonds [15]. Thus, if the short bonds in glasses with different alkali are the same length, then the lengths of the long bonds may be expected to also be the same. It is reasonable that the Te-O distribution is the same in two glasses with different alkali cations, but with the same alkali content, since its behaviour at short range depends principally on the charge on the modifier cation, not its size. Raman spectra support this assumption $[10,23]$; the relative intensities of vibrations assigned to $\left[\mathrm{TeO}_{3}\right]$ and $\left[\mathrm{TeO}_{4}\right]$ units for alkali tellurite glasses with a particular $x$ have been shown to be similar, regardless of the alkali type. Thus the first requirement (F1 - see above) for a reliable isostoichiometric difference calculation is satisfied. To investigate the second requirement $(\mathrm{F} 2)$, the difference function $\Delta T(r)_{\mathrm{Na}-\mathrm{K}}$ was simulated from the crystalline correlation functions (see Figure 6b). The comparison of the simulated difference shown in Figure 6b, with the individual $\mathrm{M}-\mathrm{O}$ contributions, shows that the difference gives a good measure of the main $\mathrm{Na}-\mathrm{O}$ peak, underestimating its area (and coordination number) by a modest amount. However, the high $r$ tail of the $\mathrm{Na}-\mathrm{O}$ distribution overlaps greatly with the main $\mathrm{K}-$ O peak, with the result that neither can be estimated reliably from the difference. The effect of this overlap between the $\mathrm{Na}-\mathrm{O}$ and $\mathrm{K}-\mathrm{O}$ peak must be taken into account if a reliable measure of $n_{\mathrm{Na}-\mathrm{O}}$ is to be made. The result obtained by direct fitting of the $\mathrm{Na}-\mathrm{O}$ peak in the residual is an underestimate of the true coordination number.

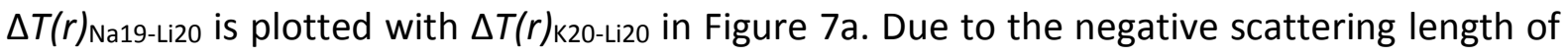
$\mathrm{Li}$, the differences are comprised of two positive peaks for $\mathrm{Li}-\mathrm{O}$ and $\mathrm{Na}-\mathrm{O}$ (or $\mathrm{K}-\mathrm{O}$ ) respectively. The difference in $\mathrm{Li}-\mathrm{O}$ and $\mathrm{K}-\mathrm{O}$ bond lengths is sufficient that the two peaks are well separated in $\Delta T(r)_{\mathrm{K} 20-\mathrm{Li} 20}$ and the Li-O peak can be fitted accurately. The fit (Table 2) yields a Li-O coordination number of 3.9(1). This result is in close agreement with the lithium 
coordination number of 4 in crystalline $\mathrm{Li}_{2} \mathrm{Te}_{2} \mathrm{O}_{5}$ [22] and $\mathrm{Li}_{2} \mathrm{TeO}_{3}$ [16]. The Li-O peak in $\Delta T(r)_{\mathrm{Na19-Li20}}$ Overlaps with the shorter $\mathrm{Na}-\mathrm{O}$ bond lengths. However, the longer $\mathrm{Na}-\mathrm{O}$ bonds, which are obscured by the K-O bond distribution in $\Delta T(r)_{\mathrm{Na} 19-\mathrm{K} 20}$ (see Figure 5 ), are clearly observed. Subtracting the Li-O peak which was fitted to $\Delta T(r)_{\text {K20-Li20 }}$ from $\Delta T(r)_{\text {Na19-Li20 }}$ gives a second measure of the $\mathrm{Na}-\mathrm{O}$ bond length distribution. Figure $7 \mathrm{~b}$ shows the $\mathrm{Na}-\mathrm{O}$ peaks extracted by both methods. There is excellent agreement between the two over the range from 2.0 to $2.36 \AA$, but the peak derived from $\Delta T(r)_{\text {Na19-Li20 }}$ is broader, extending to $2.8 \AA$. Fitting the broader $\mathrm{Na}-\mathrm{O}$ peak yields a coordination number of 4.6(1).

A tellurite glass containing $10 \mathrm{~mol} \% \mathrm{Li}_{2} \mathrm{O}$ was not made, because this composition is outside the reported glass formation range [24], and so the procedure outlined above to extract the Na-O contribution to $T(r)$ for a composition of 10 mol\% $\mathrm{Na}_{2} \mathrm{O}$ by comparison with $T(r) \mathrm{s}$ for both $\mathrm{Li}$ and $\mathrm{K}$ analogues cannot be carried out. Instead, a revised value for $n_{\mathrm{NaO}}$ of 5.2(2) was calculated by refitting $\Delta T(r)_{\text {Na10-k10 }}$ with a fixed peak width of $0.161 \AA$, the value obtained from fitting $\Delta T(r)_{\text {Na19-Li20 }}$ after subtraction of the Li-O peak.

Fits to the peak at $\sim 2.8 \AA$ in $\Delta T(r)_{\mathrm{Na}-\mathrm{K}}$ and $\Delta T(r)_{\mathrm{K}-\mathrm{Li}}$ were also attempted to provide a determination of the $\mathrm{K}-\mathrm{O}$ environment, but the resultant coordination number was $\sim 2$ (details not given). This value is much smaller than the value of 6 concluded on the basis of EXAFS and X-ray diffraction [7], or the assumed value of 7 used in a combined neutron and $\mathrm{X}$-ray diffraction study [5]. Furthermore, the average $n_{\mathrm{Ko}}$ in crystalline $\mathrm{K}_{2} \mathrm{Te}_{4} \mathrm{O}_{9}$ is 6.5 [21], and therefore a value $\sim 2$ is not reasonable. As shown by the simulation of the difference for crystal structure (Figure $6 \mathrm{~b}$ ), it is probable that the most significant factor causing the $\mathrm{K}-\mathrm{O}$ coordination number to be depressed is overlap with the high $r$ side of the $\mathrm{Na}-\mathrm{O}$ distribution. Crystalline $\mathrm{Na}_{2} \mathrm{Te}_{4} \mathrm{O}_{9}[20]$ also has a small number of $\mathrm{O} . . . \mathrm{O}$ distances associated with $\left[\mathrm{NaO}_{\mathrm{n}}\right]$ units that are shorter than $3 \AA$; if similar distances occur in the sodium tellurite glass, then this would also cause the K-O peak in the difference function to be depressed. However, it should be noted that these distances only occur in cases where there is edge sharing, either between two alkali ions, or between an alkali and a tellurium atom, and therefore they are less likely to occur in a glass. Martin et al. reported two Na-O distances in sodium doped bio-active silicate glasses at distances of $\sim 2.31$ and $2.65 \AA$ [48], consistent 
with the short and long $\mathrm{Na}-\mathrm{O}$ bonds observed in $\mathrm{Na}_{2} \mathrm{Te}_{4} \mathrm{O}_{9}$. Therefore, while there is no direct evidence of longer $\mathrm{Na}-\mathrm{O}$ bonds from this work, the difficulties in extracting the $\mathrm{K}-\mathrm{O}$ coordination number, indicate that they may be present.

In summary, the final coordination number values obtained from the neutron diffraction difference method are $n_{\mathrm{LiO}}=3.9(1)$ for $20 \mathrm{~mol} \% \mathrm{Li}_{2} \mathrm{O}, n_{\mathrm{NaO}}=5.2(2)$ for $10 \mathrm{~mol} \% \mathrm{Na}_{2} \mathrm{O}$, and $n_{\mathrm{NaO}}=4.6(1)$ for $19 \mathrm{~mol} \% \mathrm{Na}_{2} \mathrm{O}$. Tagg et al. [11] have reported dynamic angle spinning NMR measurements on a series of eight sodium tellurite glasses, from 10 to $33 \mathrm{~mol} \% \mathrm{Na}_{2} \mathrm{O}$, and found that for compositions of $15 \mathrm{~mol} \% \mathrm{Na}_{2} \mathrm{O}$ and less, the deduced coordination number is $n_{\mathrm{NaO}} \sim 5.8$, but for 18 mol\% $\mathrm{Na}_{2} \mathrm{O}$ and above, values $\sim 5.4-5.5$ are obtained. The neutron diffraction results also show a drop in $n_{\mathrm{NaO}}$ at higher $\mathrm{Na}_{2} \mathrm{O}$ content, but the actual $n_{\mathrm{NaO}}$ values are somewhat lower. It should, however, be noted that the coordination numbers deduced from the NMR results are obtained by an indirect method, which relies on a correlation between isotropic shift and $\mathrm{Na}-\mathrm{O}$ coordination number determined by Koller et al. [38]. This correlation was based on ${ }^{23} \mathrm{Na}$ NMR spectroscopy of crystalline materials, and a relatively large cutoff distance of $3.4 \AA$ was used to define the $\mathrm{Na}-\mathrm{O}$ coordination number. This cutoff distance is markedly longer than the distance range studied here by neutron diffraction methods, and may be the reason why the $n_{\mathrm{NaO}}$ values obtained by Tagg et al. [11] are somewhat larger.

The results presented here show that neutron diffraction and the isostoichiometric difference method can successfully be used to investigate the coordination of alkali cations in glasses. Useful results may be obtained for the smaller alkali cations, $\mathrm{Li}^{+}$and $\mathrm{Na}^{+}$, but not for larger cations such as $\mathrm{K}^{+}$due to overlap with other contributions to the correlation function. For the investigation of Li coordination, it is more useful to take a difference with diffraction data for a corresponding glass containing an alkali cation larger than $\mathrm{Na}^{+}$, such as $\mathrm{K}^{+}$. For the investigation of $\mathrm{Na}$ coordination, it is helpful to take a difference with diffraction data for both a smaller alkali cation (i.e. $\mathrm{Li}^{+}$) and a larger alkali cation (such as $\mathrm{K}^{+}$).

\subsection{Implications for models of the glass network}

Our results on the $\mathrm{Na}-\mathrm{O}$ coordination number for bond lengths $\sim 2.35 \AA$ (see Table 2) consistently show that the coordination number for 19 mol\% $\mathrm{Na}_{2} \mathrm{O}$ is smaller than for 10 Page 14 
mol\% $\mathrm{Na}_{2} \mathrm{O}$. This is consistent with the change in coordination number derived from ${ }^{23} \mathrm{Na}$ DAS NMR measurements by Tagg et al. [11]. These NMR results show a step-like change in $n_{\mathrm{NaO}}$ between 15 and $18 \mathrm{~mol} \% \mathrm{Na}_{2} \mathrm{O}$, and Tagg et al. have postulated that this is indicative of a significant change in the local glass structure at this composition. We do not have enough information from neutron diffraction to confirm whether or not the reduction in coordination number is step-like or gradual. According to our structural model for alkali tellurites [19], there is a fraction of terminal oxygens present in amorphous $\mathrm{TeO}_{2}$ that acts as a surplus of potential NBOs to which $\mathrm{M}^{+}$alkali cations may form bonds. Thus, for low alkali content, the $\mathrm{M}^{+}$ions are bonded solely to NBOs. The surplus of terminal oxygens becomes exhausted at $14.7 \mathrm{~mol} \% \mathrm{M}_{2} \mathrm{O}$ and, in order to incorporate additional modifier, the Te coordination number then starts to reduce to provide further NBOs. However, insufficient new NBOs are formed to fully satisfy the bonding requirements of the $\mathrm{M}^{+}$ions, and hence M-BO bonds then form too. Thus it is a prediction of the model that for more than $14.7 \mathrm{~mol} \% \mathrm{M}_{2} \mathrm{O}$ there is a decline in the $\mathrm{M}-\mathrm{NBO}$ coordination number, and a growth in the $\mathrm{M}-\mathrm{BO}$ coordination number. A BO has two bonds to Te atoms with a combined valence close to two, and hence the valence which it can contribute to a M-BO bond is relatively small. Thus M-BO bonds are longer than M-NBO bonds. The observed reduction in Na-O coordination number (see Table 2) corresponds to the reduction in M-NBO coordination predicted by the model. The predicted growth in the number of M-BO bonds occurs at longer interatomic distance, and may be masked by other contributions to $T(r)$ (such as K-O bonds, or $\mathrm{O}-\mathrm{O}$ distances in $\mathrm{LiO}_{4}$ units), and hence not directly observable in our results.

For phosphate glasses, the density is a sensitive probe of changes in the structure due to the presence of terminal $\mathrm{P}=\mathrm{O}$ bonds [52]. This arises because of changes in the way that the modifier cations bond to the oxygen atoms [53]. However, the large atomic mass of tellurium ( $\sim 4$ times that of $\mathrm{P}, \mathrm{O}$ or $\mathrm{Na}$ ) has the consequence that the density of tellurite glasses is dominated by the tellurium content (see Figure 2), and hence the density is relatively insensitive to structural effects. On the other hand, parameters such as the glass transition temperature, $T_{\mathrm{g}}$, which are not so directly dependent on the atomic mass, can also be useful probes of changes in structural behaviour. For example, Fu et al. [54] recently used topological constraint theory [55] to show that changes in $T_{\mathrm{g}}$ can be predicted based Page 15 
upon the number of terminal and non-bridging oxygens in the glass. Figure 8 shows $T_{\mathrm{g}}$ values published by Mochida et al. for lithium, sodium, and potassium tellurite glasses [56]. At low modifier concentrations, there is a linear decrease in $T_{\mathrm{g}}$ for all three glass series as $\mathrm{M}_{2} \mathrm{O}$ is added to the glass. However, the rate of change of $T_{\mathrm{g}}$ for lithium and potassium glasses alters at $15 \mathrm{~mol} \% \mathrm{M}_{2} \mathrm{O}$, the composition at which the tellurium coordination number begins to decrease and $\mathrm{M}-\mathrm{BO}$ bonds start to form (Figure 8). As the tellurite network begins to depolymerise more rapidly through the formation of $\left[\mathrm{TeO}_{3}\right]$ units, the modifier plays a larger role in interlinking the network. Lithium glasses have the highest values of $T_{\mathrm{g}}$ in glasses with high modifier content because they are comprised of [ $\left.\mathrm{LiO}_{4}\right]$ units, which have strong bonds. This is analogous to four-coordinated $\mathrm{Mg}$ and $\mathrm{Ti}$, which are known to increase the durability of glasses by forming strong bonds that cross-link a modified glass network. Conversely, glasses modified by potassium have the lowest $T_{\mathrm{g}}$ as $\mathrm{K}$ ions form the greatest number of bonds, which are correspondingly weaker.

The alteration in the modifier environment at $\sim 15$ mol\% $\mathrm{M}_{2} \mathrm{O}$ can be applied to explain changes, reported in the literature, for a range of physical properties of alkali tellurites. For example, there has been debate about the behaviour of the AC conductivity of tellurite glasses, and it is believed that this behaviour arises from "structural peculiarities of the tellurite glasses" [57-59]. The conductivity of lithium tellurite glass with 10 mol\% $\mathrm{Li}_{2} \mathrm{O}$ is markedly lower than for glasses with 15 mol\% $\mathrm{Li}_{2} \mathrm{O}$ or greater [60], and our model provides a simple interpretation of this result in which $\mathrm{Li}^{+}$ions that are bonded to bridging oxygens are more mobile than $\mathrm{Li}^{+}$ions which are solely bonded to NBOs. The model also gives an interpretation of the change in the activation energy of enthalpy relaxation and the mean square displacement of Te as measured by Mossbauer in sodium tellurite glasses [61-63].

This work supports the idea that our model, which was proposed to explain the Te-O coordination numbers for a range of potassium tellurite glasses [19], can be applied to all binary alkali tellurites and may be used to explain changes in both the structural and physical properties of the glasses with composition. However, further systematic studies of the tellurium environment in another alkali tellurite glass system would confirm this conclusion. 


\section{Conclusions}

Neutron correlation functions for five alkali tellurite glasses, $x \mathrm{M}_{2} \mathrm{O} .(1-\mathrm{x}) \mathrm{TeO}_{2}$, modified by 10 and 20 mol\% $\mathrm{K}_{2} \mathrm{O}, 10$ and $19 \mathrm{~mol} \% \mathrm{Na}_{2} \mathrm{O}$, and $20 \mathrm{~mol} \%{ }^{7} \mathrm{Li}_{2} \mathrm{O}$, have been measured. By using data for tellurite glasses with equal $x$, but different $M$, the coordination number, bond length and width of the first coordination shell for $\mathrm{Na}-\mathrm{O}$ at two compositions were extracted, along with the equivalent information for lithium in the 20 mol\% $\mathrm{Li}_{2} \mathrm{O}$ lithium tellurite glass. The positions and widths of the $\mathrm{M}-\mathrm{O}$ peaks determined by this method are consistent with the environments in the analogous crystals, as well as with results reported previously. The extraction of sensible $n_{\text {MO }}$ values indicates that the assumption that the TeO environment is independent of the modifier used is valid and allows the potassium tellurite model to be used to explain the changes in the sodium environment with composition. The decrease in $n_{\mathrm{NaO}}$ between the $\mathrm{Na} 10$ and $\mathrm{Na} 19$ compositions confirms the origin of the change in chemical shift observed by ${ }^{23} \mathrm{Na} N M R$ for sodium tellurites [11] and the reason for the change is attributed to the presence of terminal oxygens in the tellurite glass network [19]. The changes in $T_{\mathrm{g}}$ observed in alkali tellurites are also linked to the interaction between the modifier and the tellurite glass network.

Acknowledgements: Experiments at the ISIS Pulsed Neutron and Muon Source were supported by beamtime allocations (RB7739, RB9151 and RB20359) from the Science and Technology Facilities Council (STFC). Initial work for this paper was funded via an STFC PhD studentship through the Centre for Material Physics and Chemistry (CMPC04108). EPSRC are thanked for partial funding of the NMR equipment used.

\section{Appendix 1: Calculation of $\delta_{\text {iso }}$ at $14.1 \mathrm{~T}$ for 10 and $19 \mathrm{~mol} \% \mathrm{Na}_{2} \mathrm{O}$ tellurite glasses}

Tagg et al. [11] used dynamic-angle-spinning (DAS) NMR to measure $\delta_{180}$, the total isotropic shift for

${ }^{23} \mathrm{Na}$ in a sodium tellurite glass. This is given by the sum of the isotropic chemical shift and the quadrupolar induced shift:

$\delta_{180}=\delta_{180}^{(C S)}-\delta_{Q 15}$

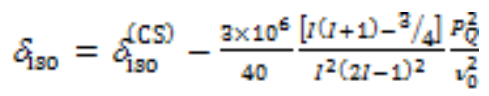


$=\oint_{1 s 0}^{(C S)}-\frac{10^{6}}{40} \times \frac{P_{Q}^{2}}{v_{0}^{2}}$

where the nuclear spin $I=3 / 2$ for ${ }^{23} \mathrm{Na}$ and the isotropic chemical shift, $\delta_{1 \mathrm{iso}}^{(\mathrm{CS})}$, and quadrupole product, $P_{\mathrm{Q}}$, are characteristic of a sodium site in the glass. The Larmor frequency, $v_{0}$, depends on the applied magnetic field and Tagg et al. [11] performed the measurements on the sodium tellurite samples at two fields $(7.1 \mathrm{~T}$ and $8.4 \mathrm{~T})$ in order to extract values for $\delta_{180}^{(\mathrm{CS})}$ and $P_{\mathrm{Q}}$ for each glass composition. Using the values which they obtained for the 10 and 20 mol\% $\mathrm{Na}_{2} \mathrm{O}$ samples, we can calculate $\delta_{\text {iso }}$ values at $14.1 \mathrm{~T}$, the magnetic field used in the current study to characterise the 10 and $19 \mathrm{~mol} \% \mathrm{Na}_{2} \mathrm{O}$ tellurite glasses (Table A1). To be comparable with the values reported in this study, $7.2 \mathrm{ppm}$ has been added to the calculated values to adjust from solid $\mathrm{NaCl}$ to $0.1 \mathrm{M} \mathrm{NaCl}$ reference.

\section{Appendix 2: Broadening for $T(r)$ simulations}

For the simulations of $T(r)$ shown in Figure 6, the effect of real-space resolution was simulated using the Lorch function [31] with a value of $35 \AA^{-1}$ for $Q_{\max }$, the same as for the experimental data on the glass samples.

Table A2 gives the parameter values used to simulate the effects of thermal motion for the simulations of $T(r)$. The root mean square (RMS) variation, $\left\langle u_{W}^{2}\right)^{1 / 2}$, in the distance between two atoms $l$ and $l^{\prime}$, varies with interatomic distance, due to the effect of correlated thermal motion [64]. For example, if two atoms are bonded then they tend to move as a pair, and so there is a smaller amount of thermal variation in their separation. On the other hand, if two atoms are more widely separated, and not directly connected by bonds, then their thermal motions are essentially independent, and there is more variation in their separation. For conventional crystallography, the effects of thermal motion on the diffraction pattern depend on the long range value of $\left\langle u_{W v}^{2}\right)^{12}$, and hence on the independent RMS displacements of the atoms.

Table A2 gives the $r$-dependent values of $\left\langle u_{w}^{2}\right)^{1 / 2}$ which were used to perform the simulations of $T(r)$ shown in Figure 6 . The crystallographic thermal factors reported for $\mathrm{Na}_{2} \mathrm{Te}_{4} \mathrm{O}_{9}$ [20] 
were used to determine the long range values of $\left\langle u_{W}^{2}\right)^{1 / 2}$ for all atom pairs. In addition the values of $\left\langle u_{W}^{2}\right)^{1 / 2}$ previously determined for short range Te-O and $\mathrm{O}-\mathrm{O}$ distances in crystalline $\alpha-\mathrm{TeO}_{2}$ [15] were used. The value used for the thermal variation in $\mathrm{M}-\mathrm{O}$ bond lengths, $\left(u_{\mathrm{MO}}^{2}\right)^{1 / 2}$, was estimated by first taking the widths ( 0.122 and $0.140 \AA$ ) of the Na-O peaks fitted to $\Delta T(r)_{\mathrm{Na}-\mathrm{K}}$ (see Table 2). In crystalline $\mathrm{Na}_{2} \mathrm{Te}_{4} \mathrm{O}_{9}$ [20], the RMS static variation in shorter $\mathrm{Na}-\mathrm{O}$ bond lengths (i.e. the bond lengths that give rise to the main peak in $T(r)$ ) is $0.053 \AA$ (see main text). It was then assumed that the static variation in $\mathrm{Na}-\mathrm{O}$ bond length in the glass is the same as in this crystal, in which case the RMS variation in $\mathrm{Na}-\mathrm{O}$ bond length is $0.12 \AA$ $\left(\left\langle u_{\text {total }}^{2}\right\rangle=\left\langle u_{\text {thermal }}^{2}\right\rangle+\left\langle u_{\text {static }}^{2}\right\rangle\right)$. 


\section{Tables}

\begin{tabular}{|l|l|l|l|l|l|}
\hline $\begin{array}{l}\text { Sample } \\
\text { name }\end{array}$ & $\begin{array}{l}\text { Nominal } \\
\text { composition } \\
\left(\mathrm{mol} \% \mathrm{Na}_{2} \mathrm{O}\right)\end{array}$ & $\begin{array}{l}\text { Density } \\
\left(\mathrm{g} \mathrm{cm}^{-3}\right)\end{array}$ & $\begin{array}{l}\text { Position of } \\
\text { NMR peak } \\
\text { maximum } \\
(\mathrm{ppm})\end{array}$ & $\begin{array}{l}\text { Composition } \\
\text { from density } \\
\left(\mathrm{mol}_{\mathrm{Na}} \mathrm{O}\right)\end{array}$ & $\begin{array}{l}\text { Composition from } \\
\text { quantitative NMR } \\
\left(\mathrm{mol}_{\mathrm{Na}} \mathrm{Na}_{2} \mathrm{O}\right)\end{array}$ \\
\hline $\mathrm{Na} 10$ & 10 & $5.29(1)$ & $-2.0(5)$ & $9.5(5)$ & $10.5(5)$ \\
\hline $\mathrm{Na} 19$ & 20 & $4.93(1)$ & $0.8(5)$ & $18.8(5)$ & $18.8(5)$ \\
\hline
\end{tabular}

Table 1: The nominal compositions, measured densities and ${ }^{23} \mathrm{Na}$ NMR peak position of the two sodium tellurite glass samples. Revised compositions, calculated by comparison with literature densities and from quantitative ${ }^{23} \mathrm{Na} \mathrm{NMR}$ respectively, are also given.

\begin{tabular}{|l|l|l|l|}
\hline Sample composition & $r_{\mathrm{MO}}(\AA)$ & $\left\langle u_{\mathrm{MO}}^{2}\right)^{1 / 2}(\AA)$ & $n_{\mathrm{MO}}$ \\
\hline \multicolumn{4}{|l|}{ Fits to Na-O peaks in $\Delta T(r)_{\mathrm{Na}-\mathrm{K}}$} \\
\hline Na10 & $2.343(5)$ & $0.122(3)$ & $4.4(1)$ \\
\hline Na19 & $2.350(5)$ & $0.140(3)$ & $4.1(1)$ \\
\hline Fits to main Te-O peak in $T(r)$ \\
\hline Na10 & $1.901(1)$ & $0.071(1)$ & $2.39(1)$ \\
\hline Na19 & $1.887(1)$ & $0.069(1)$ & $2.36(1)$ \\
\hline K10 & $1.898(1)$ & $0.066(1)$ & $2.33(2)$ \\
\hline K20 & $1.882(1)$ & $0.066(1)$ & $2.23(2)$ \\
\hline Fits to M-O peaks using $\Delta T(r)_{\mathrm{K}-\mathrm{Li}}$ and $\Delta T(r)_{\mathrm{Na}-\mathrm{Li}}$ \\
\hline Li20 (Li-O peak) & $2.078(2)$ & $0.169(3)$ & $3.9(1)$ \\
\hline Na10 (Na-O peak) & $2.37(1)$ & 0.161 & $5.2(2)$ \\
\hline Na19 (Na-O peak) & $2.37(1)$ & $0.161(1)$ & $4.6(1)$ \\
\hline
\end{tabular}

Table 2: Parameters for peak fits to the correlation functions (average bond length, RMS bond length variation and coordination number). See text for details. $\mathrm{M}$ indicates a cation ( $\mathrm{Na}, \mathrm{Te}$ or $\mathrm{Li})$. 
Page 21 


\begin{tabular}{|c|c|c|c|c|}
\hline \multirow[b]{2}{*}{ Field (T) } & \multirow[b]{2}{*}{$\begin{array}{l}\text { Larmor freq. } v_{0} \\
\qquad(\mathrm{MHz})\end{array}$} & \multirow{2}{*}{$\begin{array}{c}1 / \mathrm{vo}_{0}^{2} \\
\left(\mathrm{MHz}^{-2}\right)\end{array}$} & \multicolumn{2}{|c|}{$\delta_{\text {iso }}(\mathrm{ppm}$ wrt solid $\mathrm{NaCl}$ ) [20] } \\
\hline & & & $\begin{array}{c}10 \mathrm{~mol} \% \mathrm{Na}_{2} \mathrm{O} \\
\mathrm{P}_{\mathrm{Q}}=1.4 \pm 0.3 \mathrm{MHz}[20]\end{array}$ & $\begin{array}{c}20 \mathrm{~mol} \% \mathrm{Na}_{2} \mathrm{O} \\
\mathrm{P}_{\mathrm{Q}}=1.9 \pm 0.3 \mathrm{MHz}[20]\end{array}$ \\
\hline 7.1 & 79.4 & $1.58610^{-4}$ & $-18.8 \pm 0.8$ & $-19.0 \pm 0.8$ \\
\hline 8.4 & 95.2 & $1.10310^{-4}$ & $-16.5 \pm 0.8$ & $-14.8 \pm 0.8$ \\
\hline \multirow{3}{*}{14.1} & \multirow{3}{*}{158.747} & \multirow{3}{*}{$0.39710^{-4}$} & $-12.9 \pm 3^{a}$ & $-8.6 \pm 3^{a}$ \\
\hline & & & $-5.7 \pm 3^{b}$ & $-1.4 \pm 3^{b}$ \\
\hline & & & $-2.1 \pm 0.5^{c}$ & $+0.2 \pm 0.5^{c}$ \\
\hline
\end{tabular}

Table A1: Information used to calculate the values of $\delta_{\text {iso }}$

a values calculated using the values of $\delta_{180}^{(C S)}$ and $P_{Q}$ given in [20].

${ }^{b}$ values obtained after addition of $+7.2 \mathrm{ppm}$ to convert from solid $\mathrm{NaCl}$ to $0.1 \mathrm{M} \mathrm{NaCl}$ reference.

${ }^{c}$ values reported in the current study. These centre of gravity values are a reasonable approximation to the $\delta_{\text {iso }}$ parameter obtained by DAS. 


\begin{tabular}{|c|c|c|c|}
\hline Atom pair & Type of interaction & Interatomic distance $(\AA)$ & $\left(u_{U N^{y}}^{2}\right)^{1 / 2}(\AA)$ \\
\hline $\mathrm{Te}-\mathrm{O}$ & short bond & $<1.977^{d}$ & $0.048^{\mathrm{a}}$ \\
\hline $\mathrm{Te}-\mathrm{O}$ & long bond & $\begin{array}{l}1.977^{\mathrm{d}}-2.230 \text { in } \mathrm{Na}_{2} \mathrm{Te}_{4} \mathrm{O}_{9} \\
1.977^{\mathrm{d}}-2.300 \text { in } \mathrm{K}_{2} \mathrm{Te}_{4} \mathrm{O}_{9}\end{array}$ & $0.083^{\mathrm{a}}$ \\
\hline $\mathrm{Te}-\mathrm{O}$ & not bonded & $\begin{array}{l}>2.230 \text { in } \mathrm{Na}_{2} \mathrm{Te}_{4} \mathrm{O}_{9} \\
>2.300 \text { in } \mathrm{K}_{2} \mathrm{Te}_{4} \mathrm{O}_{9}\end{array}$ & $0.134^{\mathrm{b}}$ \\
\hline $\mathrm{O}-\mathrm{O}$ & $\mathrm{O}-\mathrm{Te}-\mathrm{O}$ link & $<3.240$ & $0.100^{\mathrm{a}}$ \\
\hline $\mathrm{O}-\mathrm{O}$ & not linked & $>3.240$ & $0.147^{b}$ \\
\hline $\mathrm{M}-\mathrm{O}$ & bonded & $\begin{array}{l}<2.926 \text { in } \mathrm{Na}_{2} \mathrm{Te}_{4} \mathrm{O}_{9} \\
<3.372 \text { in } \mathrm{K}_{2} \mathrm{Te}_{4} \mathrm{O}_{9}\end{array}$ & $0.120^{c}$ \\
\hline $\mathrm{M}-\mathrm{O}$ & not bonded & 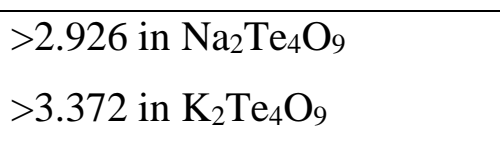 & $0.149^{b}$ \\
\hline $\mathrm{M}-\mathrm{M}$ & all & all & $0.152^{b}$ \\
\hline $\mathrm{Te}-\mathrm{Te}$ & all & all & $0.119^{b}$ \\
\hline Te-Na & all & all & $0.136^{\mathrm{b}}$ \\
\hline
\end{tabular}

Table A2: The thermal parameters used to simulate $T(r)$ for crystalline $\mathrm{M}_{2} \mathrm{Te}_{4} \mathrm{O}_{9}(\mathrm{M}=\mathrm{Na}$ or $\mathrm{K}$ ).

$\left\langle u_{l l}^{2}\right)^{1 / 2}$ is the RMS variation in interatomic distance between the pair of atoms $l$ and $l^{\prime}$.

${ }^{a}$ value taken from Barney et al. [15]

${ }^{b}$ value derived from the crystallographic thermal parameters reported by Tagg et al. [20]

'value estimated in this study; see text in Appendix 2

${ }^{d}$ the Te-O bond-valence parameter [46] 


\section{References}

[1] S. Neov, A.V. Kozhukharov, A.I. Gerasimova, A.K. Krezhov, A.B. Sidzhimov, J. Phys. C, 12 (1979) 2475.

[2] J.C. McLaughlin, S.L. Tagg, J.W. Zwanziger, D.R. Haeffner, S.D. Shastri, J. Non-Cryst. Solids, 274 (2000) 1.

[3] J.C. McLaughlin, S.L. Tagg, J.W. Zwanziger, J. Phys. Chem., 105 (2001) 67.

[4] H. Niida, T. Uchino, J.S. Jin, S.H. Kim, T. Fukunaga, T. Yoko, J. Chem. Phys., 114 (2001) 459.

[5] U. Hoppe, I. Gugov, H. Burger, P. Jovari, A.C. Hannon, J. Phys.: Condens. Matter, 17 (2005) 2365.

[6] Y. Iwadate, T. Mori, T. Hattori, S. Nishiyama, K. Fukushima, N. Umesaki, R. Akagi, K. Handa, N. Ohtori, T. Nakazawa, A. Iwamoto, J. Alloys Compd., 311 (2000) 153.

[7] R. Akagi, K. Handa, N. Ohtori, A.C. Hannon, M. Tatsumisago, N. Umesaki, Jpn. J. Appl. Phys., 38 Suppl. 38-1 (1999) 160.

[8] Y. Shimizugawa, T. Maeseto, S. Suehara, S. Inoue, A. Nukui, J. Mater. Res., 10 (1995) 405.

[9] O. Noguera, T. Merle-Mejean, A.P. Mirgorodsky, M.B. Smirnov, P. Thomas, J.C. Champarnaud, J. Non-Cryst. Solids, 330 (2003) 50.

[10] T. Sekiya, N. Mochida, A. Ohtsuka, M. Tonokawa, J. Non-Cryst. Solids, 144 (1992) 128.

[11] S.L. Tagg, R.E. Youngman, J.W. Zwanziger, J. Phys. Chem., 99 (1995) 5111.

[12] J.W. Zwanziger, J.C. McLaughlin, S.L. Tagg, Phys. Rev. B: Condens. Matter, 56 (1997) 5243.

[13] D. Holland, J. Bailey, G. Ward, B. Turner, P. Tierney, R. Dupree, Solid State Nucl. Magn. Reson., 27 (2005) 16.

[14] H. Munemura, K. Mitome, M. Misawa, K. Maruyama, J. Non-Cryst. Solids, 293 (2001) 700.

[15] E.R. Barney, A.C. Hannon, D. Holland, J. Phys. Chem. C, 116 (2012) 3707.

[16] F. Folger, Z. Anorg. Allg. Chem., 411 (1975) 103.

[17] R. Masse, J.C. Guitel, I. Tordjman, Mat. Res. Bull., 15 (1980) 431.

[18] L. Andersen, V. Langer, A. Stromberg, D. Stromberg, Acta Cryst. B, 45 (1989) 344.

[19] E.R. Barney, A.C. Hannon, D. Holland, N. Umesaki, M. Tatsumisago, R.G. Orman, S. Feller, J. Phys. Chem. Lett., 4 (2013) 2312.

[20] S.L. Tagg, J.C. Huffman, J.W. Zwanziger, Chem. Mater., 6 (1994) 1884.

[21] C.R. Becker, S.L. Tagg, J.C. Huffman, J.W. Zwanziger, Inorg. Chem., 36 (1997) 5559.

[22] D. Cachau-Herreillat, A. Norbert, M. Maurin, E. Philippot, J. Solid State Chem., 37 (1981) 352.

[23] A.G. Kalampounias, S. Boghosian, Vib. Spectroscop., 59 (2012) 18.

[24] O.V. Mazurin, M.V. Streltsina, T.P. Shaiko-Shvaikovskaya, Handbook of glass data. Part B, Single-component and binary non-silicate oxide glasses, Elsevier, Amsterdam, 1985. 
[25] K.J.D. Mackenzie, M.E. Smith, Multinuclear Solid-state NMR of Inorganic Materials, Pergamon, Oxford, 2002.

[26] A.C. Hannon, Nucl. Instrum. Meth. A, 551 (2005) 88.

[27] A.K. Soper, Rutherford Appleton Laboratory Technical Report, RAL-TR-2011-013, 2011

[28] A.C. Hannon, W.S. Howells, A.K. Soper, IOP Conf. Ser., 107 (1990) 193.

[29] W.S. Howells, A.C. Hannon, J. Phys.: Condens. Matter, 11 (1999) 9127.

[30] A.C. Hannon, Neutron diffraction database, http://www.alexhannon.co.uk/DBindex.htm, last accessed: 09/09/2014

[31] E. Lorch, J. Phys. C, 2 (1969) 229.

[32] A.C. Hannon, in: M. Affatigato (Ed.), Modern glass characterization, Wiley, New York, 2015, p. in press.

[33] A.K. Yakhkind, N.S. Martyshchenko, Neorg. Mater., 6 (1970) 1459.

[34] A.G. Vlasov, V.A. Florinskaya, A.A. Venediktov, E.P. Zubareva, R.I. Kurtsinovskaya, V.N. Morozov, E.V. Smirnova, A.K. Yakhkind, Structure, and physical and chemical properties of inorganic glasses, in Russian, Leningrad, 1974.

[35] V.V. Ipatjeva, Y.B. Dimitriev, C. R. Acad. Bulg. Sci., 28 (1975) 371.

[36] E.R. Barney, A.C. Hannon, D. Holland, Phys. Chem. Glasses: Eur. J. Glass Sci. Technol. B, 50 (2009) 156.

[37] V.F. Sears, Neutron News, 3 (1992) 26.

[38] H. Koller, G. Engelhardt, A.P.M. Kentgens, J. Sauer, J. Phys. Chem., 98 (1994) 1544.

[39] A.C. Wright, A.G. Clare, B. Bachra, R.N. Sinclair, A.C. Hannon, B. Vessal, Trans. ACA 27 (1991) 239.

[40] H.E. Fischer, A.C. Barnes, P.S. Salmon, Rep. Prog. Phys., 69 (2006) 233.

[41] A. Lee, G. Etherington, C.N.J. Wagner, J. Non-Cryst. Solids, 61-2 (1984) 349.

[42] L.B. Skinner, C.J. Benmore, J.K.R. Weber, J. Du, J. Neuefeind, S.K. Tumber, J.B. Parise, Phys. Rev. Lett., 112 (2014) 157801.

[43] R.A. Martin, P.S. Salmon, H.E. Fischer, G.J. Cuello, J. Phys.: Condens. Matter, 15 (2003) 8235.

[44] R.A. Martin, P.S. Salmon, C.J. Benmore, H.E. Fischer, G.J. Cuello, Phys. Rev. B, 68 (2003) 054203.

[45] K. Wezka, A. Zeidler, P.S. Salmon, P. Kidkhunthod, A.C. Barnes, H.E. Fischer, J. NonCryst. Solids, 357 (2011) 2511.

[46] N.E. Brese, M. O'Keeffe, Acta Cryst. B, 47 (1991) 192.

[47] R. Shannon, Acta Cryst. A, 32 (1976) 751.

[48] R.A. Martin, H.L. Twyman, G.J. Rees, J.M. Smith, E.R. Barney, M.E. Smith, J.V. Hanna, R.J. Newport, Phys. Chem. Chem. Phys., 14 (2012) 12105.

[49] R.A. Martin, H.L. Twyman, G.J. Rees, E.R. Barney, R.M. Moss, J.M. Smith, R.G. Hill, G. Cibin, T. Charpentier, M.E. Smith, J.V. Hanna, R.J. Newport, J. Mater. Chem., 22 (2012) 22212.

[50] A.C. Hannon, Rutherford Appleton Laboratory Report, RAL-93-063, 1993

[51] E.R. Barney, Ph.D. thesis in Physics, University of Warwick, 2008.

[52] R.K. Brow, C.A. Click, T.M. Alam, J. Non-Cryst. Solids, 274 (2000) 9.

[53] U. Hoppe, J. Non-Cryst. Solids, 195 (1996) 138.

[54] A.I. Fu, J.C. Mauro, J. Non-Cryst. Solids, 361 (2013) 57. 
[55] P.K. Gupta, J.C. Mauro, J. Chem. Phys., 130 (2009) 094503.

[56] N. Mochida, K. Takahahi, K. Nakata, S. Shibusawa, J. Ceram. Soc. Jpn., 86 (1978) 316.

[57] S. Murugavel, B. Roling, Phys. Rev. Lett., 89 (2002) 195902.

[58] A. Ghosh, S. Bhattacharya, Phys. Rev. Lett., 91 (2003) 049601.

[59] S. Murugavel, B. Roling, Phys. Rev. Lett., 91 (2003) 049602.

[60] A. Ghosh, A. Pan, Phys. Rev. Lett., 84 (2000) 2188.

[61] M. Zhang, P. Boolchand, Science, 266 (1994) 1355.

[62] J.W. Zwanziger, S.L. Tagg, J.C. Huffman, Science, 268 (1995) 1510.

[63] P. Boolchand, M. Zhang, Science, 268 (1995) 1510.

[64] I.K. Jeong, T. Proffen, F. Mohiuddin-Jacobs, S.J.L. Billinge, J. Phys. Chem. A, 103 (1999) 921. 
Figures

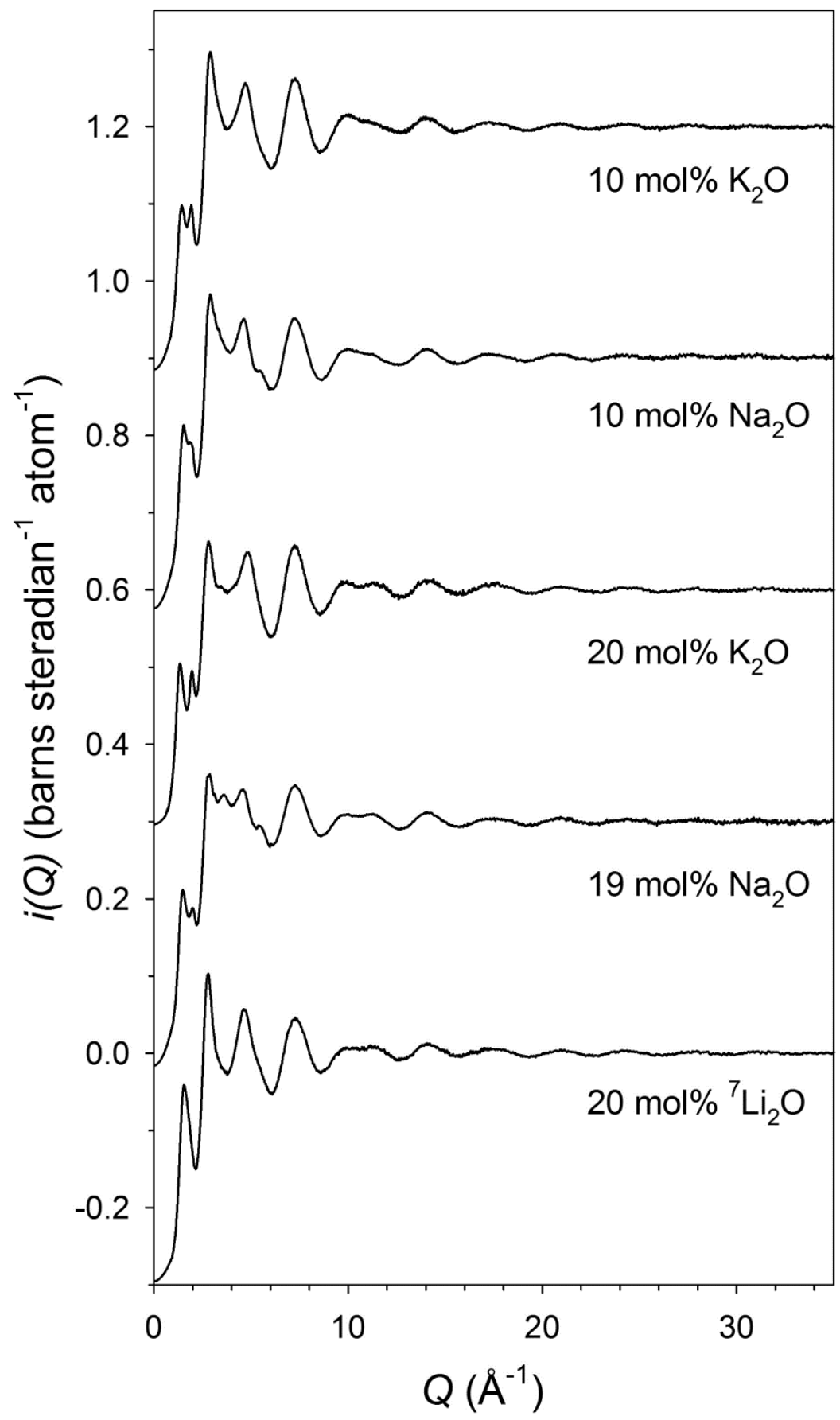

Figure 1: The neutron distinct scattering, $i(Q)$, for binary alkali tellurite glasses containing 10 mol.\% $\mathrm{K}_{2} \mathrm{O}, 10 \mathrm{~mol} . \% \mathrm{Na}_{2} \mathrm{O}, 20 \mathrm{~mol} . \% \mathrm{~K}_{2} \mathrm{O}, 19 \mathrm{~mol} . \% \mathrm{Na}_{2} \mathrm{O}$ and 20 mol.\% ${ }^{7} \mathrm{Li}_{2} \mathrm{O}$ respectively. Vertical shifts are shown between successive datasets for clarity.

Page 27 
Page 28 


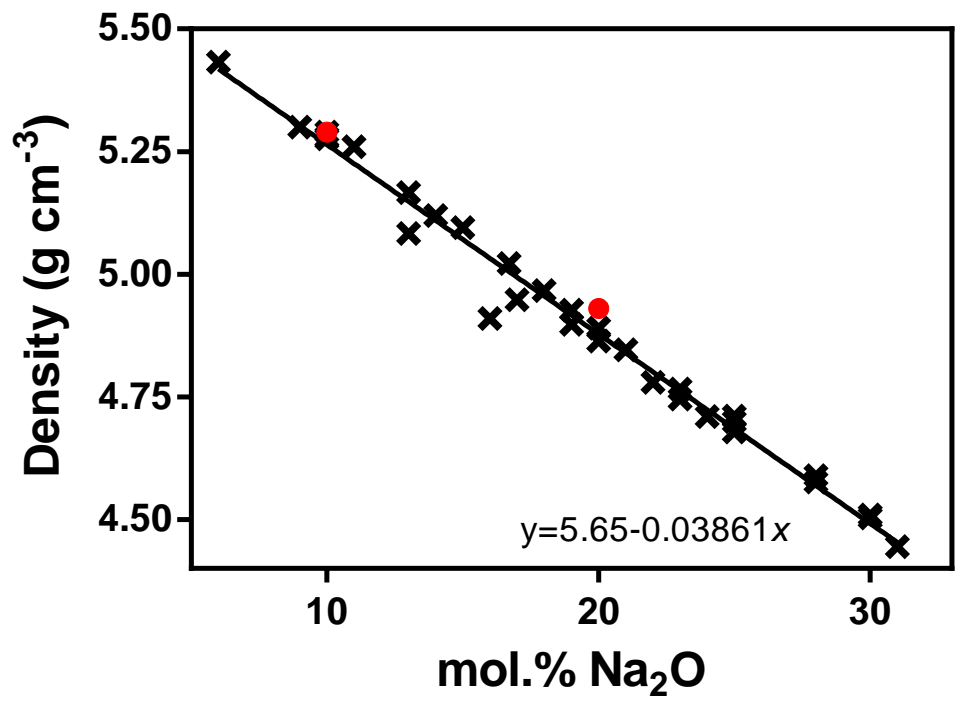

Figure 2: The densities of the two sodium tellurite glasses (red circles, plotted using the nominal composition) compared to glass densities taken from the literature (black crosses) [33-35]. The straight line is a fit to the literature values. 


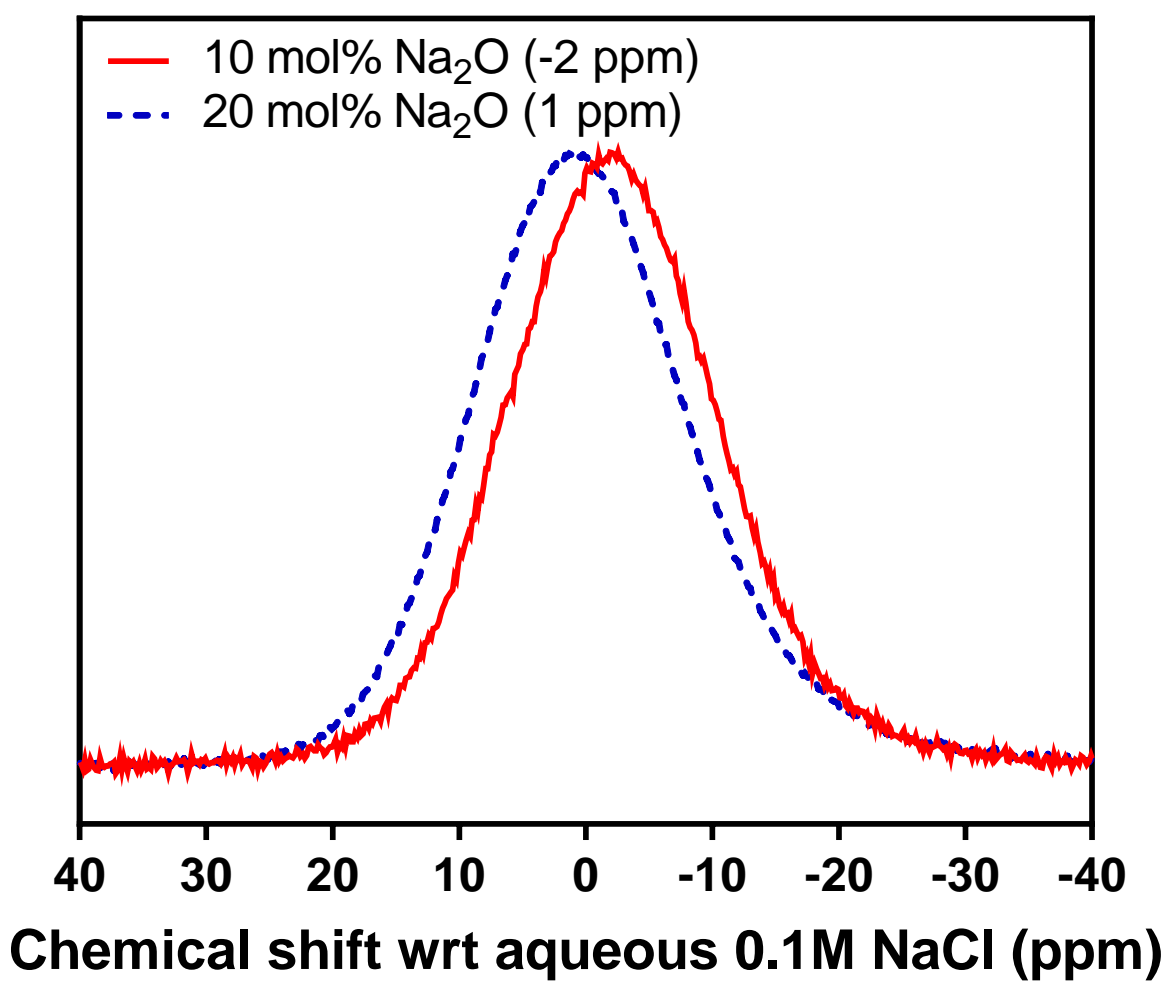

Figure 3: The NMR spectra for $\mathrm{Na10}$ (red continuous line) and Na19 (blue dashed line), normalised to the maximum intensity to aid comparison. The spectra are referenced with respect to aqueous $\mathrm{NaCl}$. 


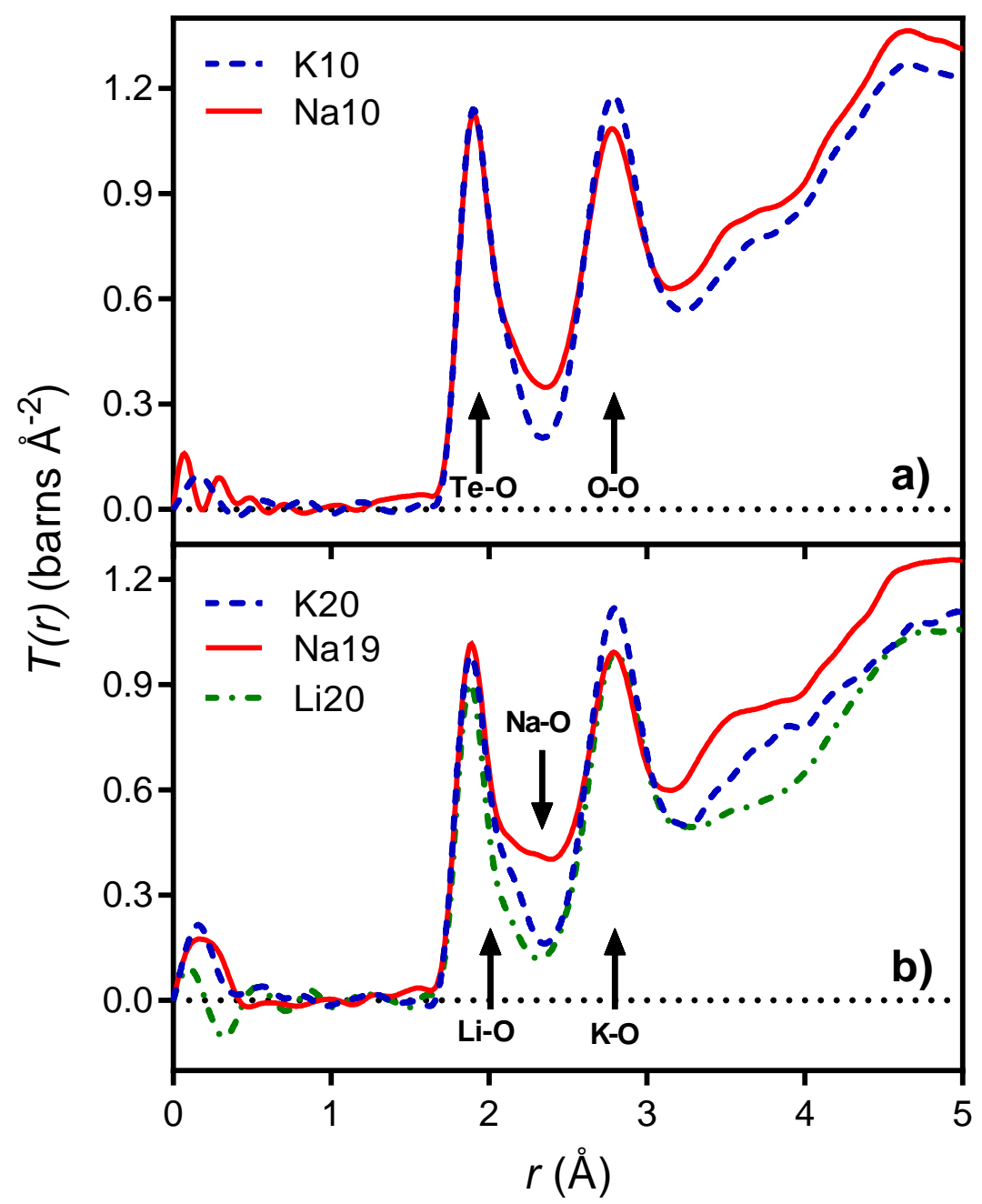

Figure 4: $T(r) s$ for potassium, sodium and lithium tellurite glasses modified with a) 10 and b) 20 mol\% $\mathrm{M}_{2} \mathrm{O}$. 


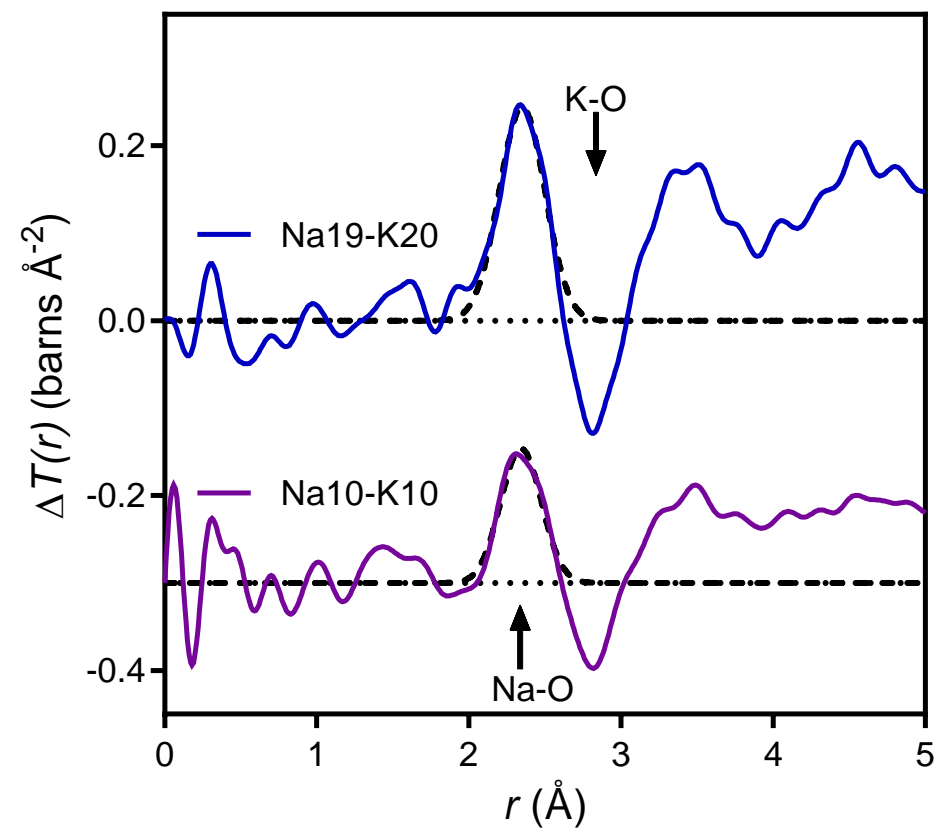

Figure 5: The difference ( $N a$ minus $\mathrm{K}$ ) between the correlation functions for sodium and potassium tellurite glasses with the same value of $x$ (i.e. the same alkali content). Also shown are fits to the $\mathrm{Na-O}$ peak (black dashed) in $\Delta T(r)_{\mathrm{Na19-K20}}$ (blue) and $\Delta T(r)_{\text {Na10-K10 }}$ (purple, shifted vertically for clarity). The black dotted line is zero. 


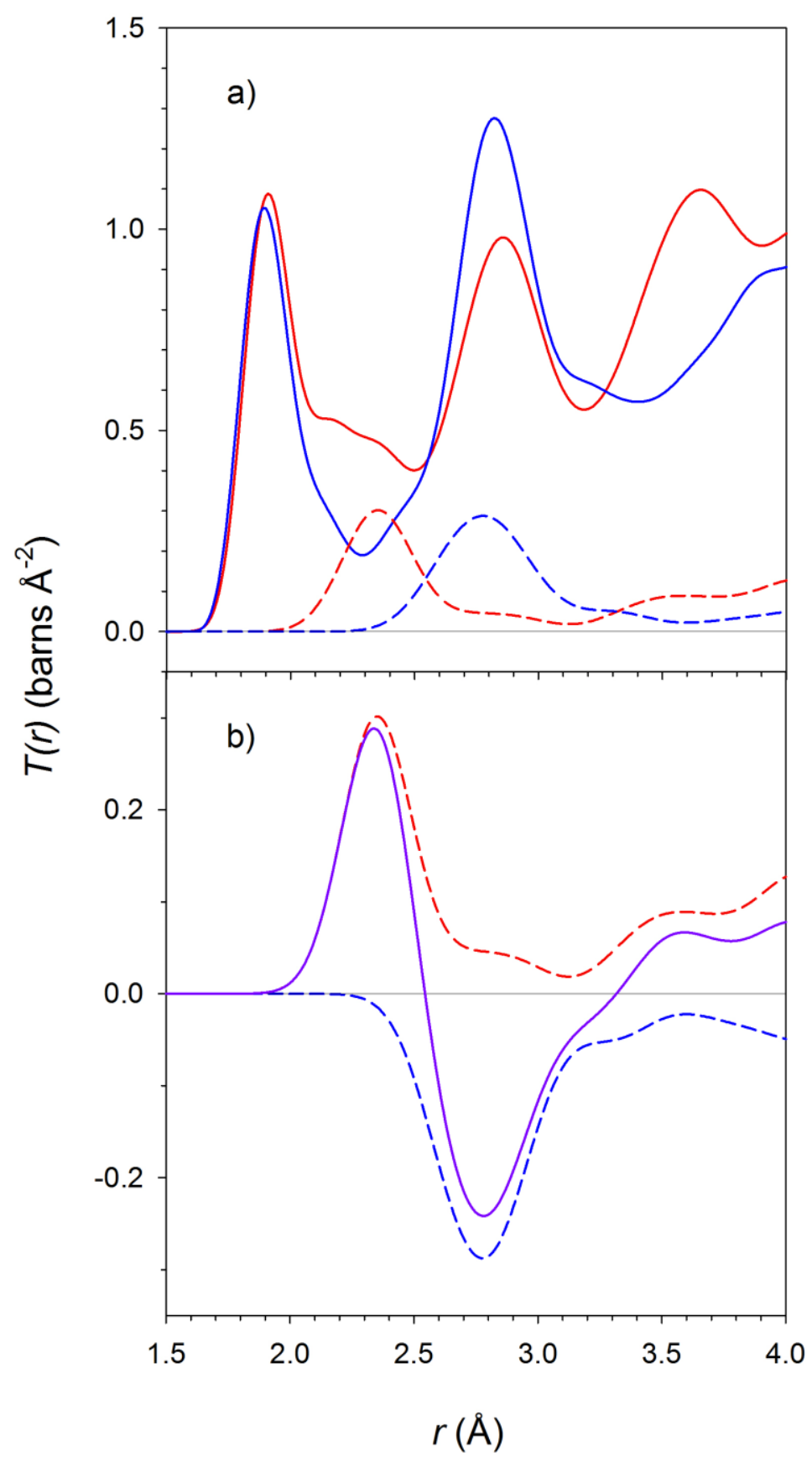

Figure 6: Simulations of the correlation functions for crystalline $\mathrm{Na}_{2} \mathrm{Te}_{4} \mathrm{O}_{9}[20]$ (red) and crystalline $\mathrm{K}_{2} \mathrm{Te}_{4} \mathrm{O}_{9}$ [21] (blue); see text for details. a) The continuous lines show the simulation of the total correlation function, $T(r)$, whilst the dashed lines show the M-O contributions, $2 c_{\mathrm{M}} \bar{b}_{\mathrm{M}} \bar{b}_{\mathrm{O}} t_{\mathrm{MO}}(r)$, to $T(r)$. b) The continuous purple line shows the simulation of the difference function, $\Delta T(r)_{\mathrm{Na}-\mathrm{K}}$ (the difference of the two M-O contributions), whilst the dashed lines show the simulation of the Page 33 
function.

Page 34 


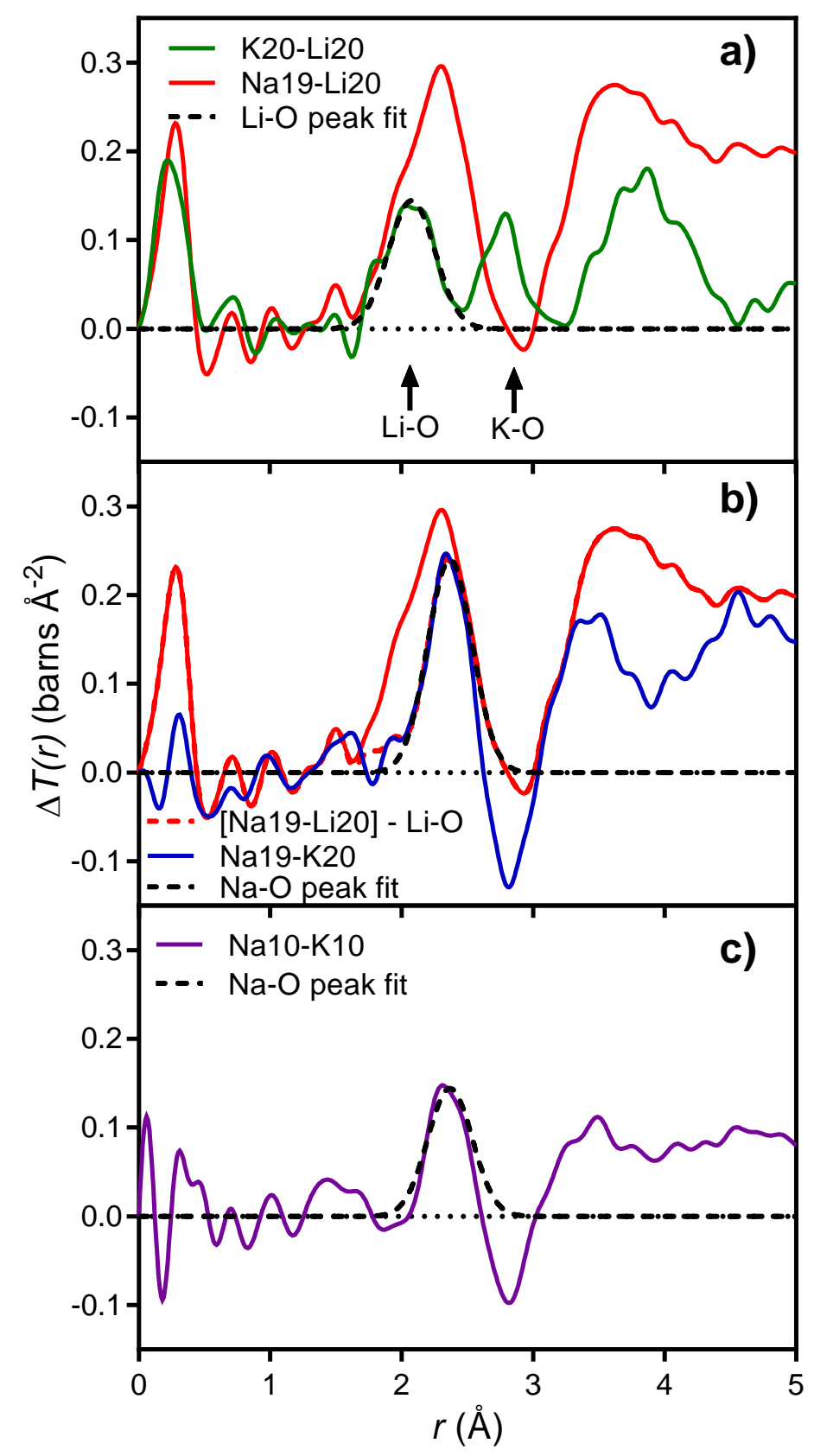

Figure 7: a) $\Delta T_{\text {Na19-Li20 }}(r)$ (red) and $\Delta T_{\text {K20-Li20 }}(r)$ (green) are plotted along with a Li-O peak fitted to the latter. b) $\Delta T_{\text {Na19-Li2o }}(r)$ before (red) and after (red dashed) subtraction of the Li-O peak fit shown in Figure 6a. The fit to the resultant $\mathrm{Na}-\mathrm{O}$ peak is also shown (black dashed) and compared to $\Delta T_{\mathrm{Na} 19}$ к20 $(r)$ (blue). c) $\Delta T_{\mathrm{Na10-k10}}(r)$ (purple) and a fit to the Na-O peak (black dashed) in which the peak width has been fixed to equal that of the $\mathrm{Na}-\mathrm{O}$ peak fit shown in Figure $6 \mathrm{~b}$.

Page 35 


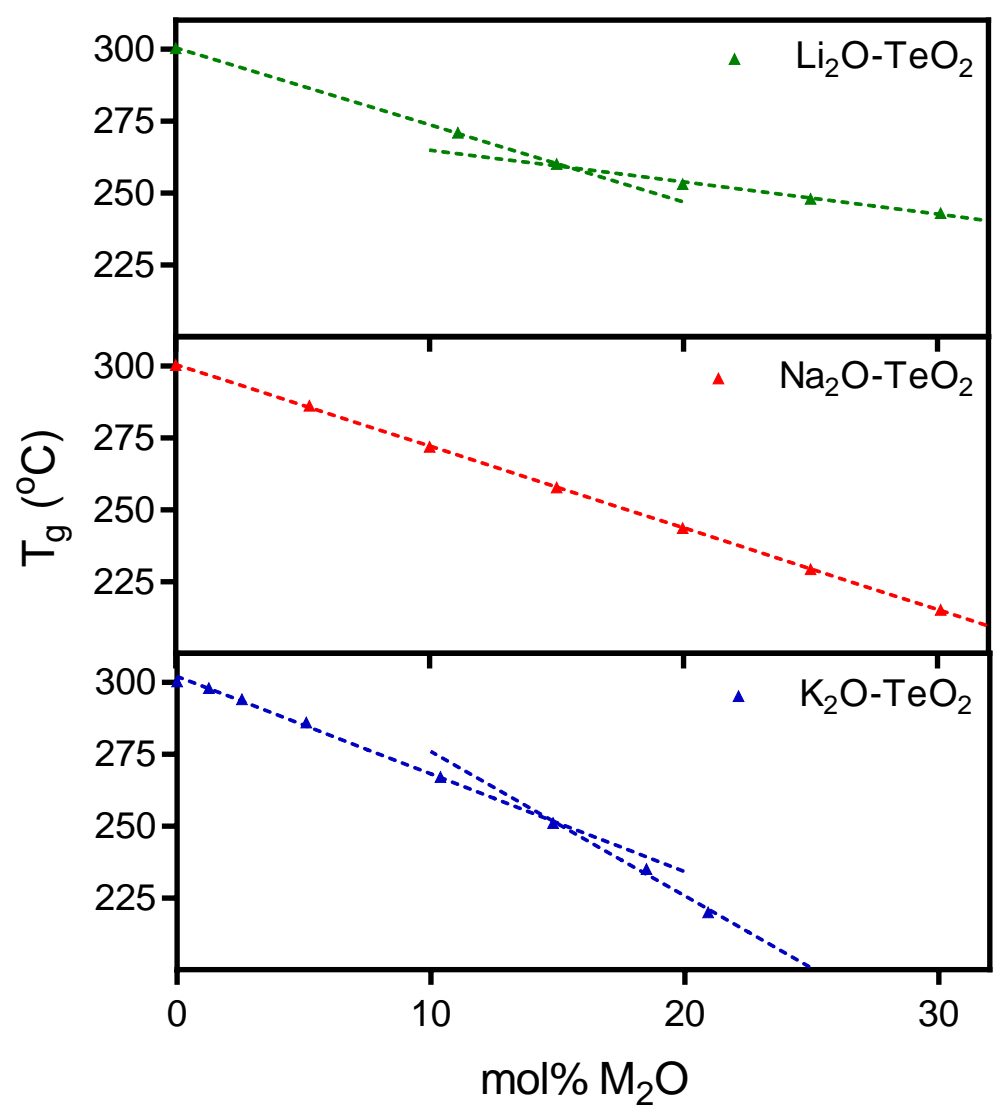

Figure 8: The glass transition temperature, $T_{\mathrm{g}}$, for lithium, sodium, and potassium tellurites, as reported by Mochida et al. [56]. 